\title{
A Mitigation Approach to Alleviate Arsenic Accumulation in Rice through Balanced Fertilization
}

\author{
S. M. Imamul Huq, ${ }^{1}$ Selina Sultana, ${ }^{2}$ Ganga Chakraborty, ${ }^{2}$ and M. T. A. Chowdhury ${ }^{2}$ \\ ${ }^{1}$ Bangladesh-Australia Centre for Environmental Research (BACER-DU), University of Dhaka, Dhaka 1000, Bangladesh \\ ${ }^{2}$ Department of Soil, Water and Environment, University of Dhaka, Dhaka 1000, Bangladesh
}

Correspondence should be addressed to S. M. Imamul Huq, imamhuq@hotmail.com

Received 8 July 2010; Revised 12 October 2010; Accepted 25 December 2010

Academic Editor: Marco Trevisan

Copyright (C) 2011 S. M. Imamul Huq et al. This is an open access article distributed under the Creative Commons Attribution License, which permits unrestricted use, distribution, and reproduction in any medium, provided the original work is properly cited.

Pot experiments with boro and aman season rice on the same soils treated with arsenic contaminated irrigation water and using balanced fertilizer or not revealed that balance fertilization could be a strategy to mitigate arsenic accumulation in rice grain. The study also revealed that there is a carryover effect of As applied through irrigation in the boro season to the subsequent aman season rice. This carryover effect too, could be minimized with balanced fertilization.

\section{Introduction}

Groundwater contamination by As in Bangladesh has been termed as one of the worst calamities of the history [1]. The majority of the extracted groundwater $(\sim 85 \%)$ is used for irrigation [2]. About 40 percent of the net cultivable area of the country is under irrigation and the major recipient $(60 \%)$ of the irrigation water is the boro rice (dry season rice) along with wheat and some other vegetable crops [3]. Irrigation with arsenic-contaminated groundwater is leading to elevated levels of arsenic in paddy soils [4], which may lead to increased concentrations of arsenic in rice [5-10], wheat $[7,8]$, vegetables $[7,8]$, and other agricultural products [11]. According to Imamul Huq et al. [8], the total arsenic loading in irrigated soils for a boro rice requiring $1000 \mathrm{~mm}$ of irrigation water per season ranges from 1.36 to $5.5 \mathrm{~kg} / \mathrm{ha} / \mathrm{yr}$. Arsenic thus accumulated in the topsoil becomes available to the next crop of rice cultivated during the aman (wet) season, even if the crop is cultivated with arsenic free irrigation water or with rainwater $[10,12]$. The carryover effects of irrigation on the subsequent accumulation of arsenic by different varieties of rice in arsenic affected areas, and its mitigation possibilities need to be properly addressed.

A number of mitigation approaches have been tried to control arsenic accumulation in plants [1, 13-15]. Use of balanced fertilizers in soil could be an approach to alleviate the accumulation of As in different varieties of rice plants. Balanced fertilization is the key to efficient fertilizer use for sustainable high yields. Field crops receiving arsenic through irrigation water might show yield differences and accumulation of the toxic element that could be avoided by proper nutrient balance in the growth medium.

The present study aims at finding the effect of balanced fertilization in the possible mitigation of arsenic accumulation in different varieties of rice in the boro season and the carryover effect of As in the aman season.

\section{Materials and Methods}

2.1. Sampling Site. Soil samples were collected from a farmer's field in Dhamrai Thana near Dhaka, Bangladesh. The geolocation of the sampling site is $23^{\circ} 54.749^{\prime} \mathrm{N}$ and $90^{\circ} 10.842^{\prime} \mathrm{E}$. The soil thus selected belongs to the Dhamrai soil series. The soil is a Typic Haplaquept [16]. The collected soil samples were processed as described elsewhere [15].

2.2. Experimental. Pot culture experiments with the collected soil samples were conducted in two consecutive rice seasons, boro (dry) and aman (wet) seasons, in the net house of the Department of Soil, Water and Environment, University of Dhaka, Bangladesh. In the boro season, arsenic 
accumulation in several varieties in the presence of balanced fertilization or not was studied, while in the following aman season, the carryover effects of the boro season As-irrigation on the accumulation of arsenic by different varieties of aman rice was studied.

2.2.1. Pot Culture Experiment with Boro Rice. For the experiment, three different varieties of boro rice (Oryza sativa L.) viz., BRRI dhan 29 (BR-29), BRRI dhan 35 (BR-35), and BRRI dhan 36 (BR-36) were used. Certified seeds of the rice varieties were collected from the Bangladesh Rice Research Institute (BRRI), Gazipur. The treatment combinations used in this experiment were as follows:

(i) absolute control (C)—no fertilizer, no added arsenic,

(ii) arsenic control (CF) - required rates of fertilizer, no added arsenic,

(iii) arsenic treatment (T) — no fertilizer, added arsenic,

(iv) fertilizer treatment (TF)_added fertilizer, added arsenic.

There were three replications for each treatment. A total of 36 pots ( 4 treatments $\times 3$ varieties $\times 3$ replications $=36$ pots) were used in this pot experiment: 12 pots for each of the rice varieties.

Five (5) $\mathrm{kg}$ sized earthen pots with no hole at the bottom were used. Four $\mathrm{kg}$ air-dried (sieved to $5 \mathrm{~mm}$ size) soil samples were put into each of the earthen pots. Seeds of BR29 , BR-35, and BR-36 were first dipped in water and kept overnight and then kept for 2 to 3 days in dark conditions for germination. Proper puddling of the pot soils was done manually. The germinated seeds of the 3 rice varieties were sown randomly in the selected pots, and only 5 rice plants were allowed to grow after the seedlings were established. All the pots were arranged in a randomized way in the net house.

Plants were watered twice daily, in the morning and in the afternoon, because of intense sunshine and warm weather. Intercultural operations were carried out whenever necessary. Weeds were removed manually. Positions of the pots were changed every alternate day to allow equal exposure of each of the pots to sunlight. Adequate plant protection measures were taken during the growing period. Different parameters like growth, appearance of any symptoms and so forth were noted during the whole growing period.

The nutritional $(\mathrm{N}, \mathrm{P}$, and $\mathrm{K}$ ) requirement of the pot soil was calculated on the basis of 'Soil Test Value Interpretation' as recommended by the Bangladesh Agriculture Research Council [17] once the soil was analysed for its N, P, and $\mathrm{K}$ status. For the calculation of the amount needed the following equation has been used [17]:

$$
\mathrm{Fr}=\mathrm{Uf}-\frac{\mathrm{Ci}}{\mathrm{Cs}} \times(\mathrm{St}-\mathrm{Ls})
$$

where Fr is fertilizer nutrient required for a given soil test value, Uf = upper limit of the recommended fertilizer nutrient for the respective Soil Test Value Interpretation (STVI) class, $\mathrm{Ci}=$ Units of class intervals used for fertilizer nutrient recommendation, $\mathrm{Cs}=$ Units of class intervals used for STVI class, $\mathrm{St}=$ Soil test value, $\mathrm{Ls}=$ Lower limit of the soil test value within STVI class.

For each of the varieties of rice, there is different STVI table. The tables are shown below as (Tables 1(a) and $1(\mathrm{~b}))$. The required amounts of fertilizer were calculated accordingly and the requisite amounts of $\mathrm{N}, \mathrm{P}$, and $\mathrm{K}$ were supplied from Urea, TSP, and MOP, respectively.

$\mathrm{N}$, $\mathrm{P}$, and $\mathrm{K}$ status of the soil was found to be low. Accordingly, $120 \mathrm{~kg} \mathrm{~N}, 25 \mathrm{~kg} \mathrm{P}$ and $85 \mathrm{~kg} \mathrm{~K}$ per ha were applied for BR 29 and $95 \mathrm{~kg} \mathrm{~N}, 13 \mathrm{~kg} \mathrm{P}$, and $55 \mathrm{~kg} \mathrm{~K}$ per ha were applied for BR 35 and BR 36, respectively.

The whole of TSP, MOP, and one-third of the urea were applied at the time of soil preparation. The second one-third of urea was applied after 35 days of sowing the seeds and the final one-third was applied during the panicle initiation stage of the rice plants.

$0.5 \mathrm{mg} \mathrm{L}^{-1}$ arsenic solution, in a combination of $80 \%$ arsenite and $20 \%$ arsenate, was used as the As treatment. Sodium meta-arsenite $\left(\mathrm{NaAsO}_{2}\right)$ and sodium arsenate $\left(\mathrm{Na}_{2} \mathrm{HAsO}_{4} \cdot 7 \mathrm{H}_{2} \mathrm{O}\right)$ were used as the sources of arsenite and arsenate, respectively.

The background level of As in the collected soil sample was $2.32 \mathrm{mg} \mathrm{kg}^{-1}$. This was taken as the control. Tap water was added to the pots with $\mathrm{C}$ and CF treatments. As-spiked water was added to the pots with $\mathrm{T}$ and $\mathrm{TF}$ treatments at every alternate day from seed sowing to seed maturity. The total amount of tap water and As-spiked water added to each of the pots was recorded. A total of $27 \mathrm{~L}$ of this As-spiked water was applied during the growing season to each of the treated pots.

The rice variety BR-29 was harvested at 140 days and BR35 and BR-36 were harvested at 120 days after germination of the seeds. At harvest, the plants from every pot were collected individually. The plants were sampled manually. The aerial parts of the plants were separated using a scissor and, afterwards, the roots were taken out from the soil. The grains were also collected. Thus, the plant samples were separated into three parts: root, straw, and grains. The roots of the sampled plants were washed first with tap water and then again with deionized distilled water three times to remove ions from the root-free space as well as to dislodge any adhering particles on the root surface. The wet samples were dried using paper towels. The samples were first air-dried and then oven-dried at $70^{\circ} \pm 5^{\circ} \mathrm{C}$ for 48 hours and the dry weight of the plant samples were noted. The dried plant samples were then ground and mixed thoroughly to make it composite and stored in a dry place for further chemical analyses.

2.2.2. Pot Culture Experiment with Aman Rice. Three different varieties of aman rice (Oryza sativa L.), namely, BRRI dhan 22 (BR-22), BRRI dhan 23 (BR-23) and BRRI dhan 25 (BR-25) were used in this experiment. Certified seeds of the rice varieties were collected from the Bangladesh Rice Research Institute (BRRI), Gazipur.

In this part of the experiment, the pots of the previous boro season experiment were used. The pots did not receive any extra treatments of arsenic. However, the soils were analyzed for fertilizer requirement. Accordingly, the fertilizer 
TABLE 1

(a) Specific fertilizer recommendation for BR 29 for high yield goal $(7.5 \pm 0.75 \mathrm{t} / \mathrm{ha})$

\begin{tabular}{lccc}
\hline Soil analysis interpretation & & Fertilizer recommendation $(\mathrm{kg} / \mathrm{ha})$ & $\mathrm{K}$ \\
\hline Optimum & $\mathrm{N}$ & $\mathrm{P}$ & $0-33$ \\
Medium & $0-56$ & $0-10$ & $34-66$ \\
Low & $57-112$ & $11-20$ & $67-99$ \\
Very low & $113-168$ & $21-30$ & $100-132$ \\
\hline
\end{tabular}

(b) Specific fertilizer recommendation for BR 35 and BR 36 for high yield goal $(5.0 \pm 0.50 \mathrm{t} / \mathrm{ha})$

\begin{tabular}{lccc}
\hline Soil Analysis Interpretation & \multicolumn{3}{c}{ Fertilizer Recommendation $(\mathrm{kg} / \mathrm{ha})$} \\
\hline Optimum & $\mathrm{N}$ & $\mathrm{P}$ & $0-20$ \\
Medium & $0-35$ & $6-5$ & $21-40$ \\
Low & $36-70$ & $6-10$ & $41-60$ \\
Very low & $71-105$ & $11-15$ & $61-80$ \\
\hline
\end{tabular}

(c) Fertilizers applied for BR-22, BR-23 and BR-25 rice during aman season

\begin{tabular}{|c|c|c|c|c|c|c|}
\hline & \multicolumn{3}{|c|}{ BR-22 and BR-23 } & \multicolumn{3}{|c|}{ BR-25 } \\
\hline & $\mathrm{N}$ & $\mathrm{P}$ & $\mathrm{K}$ & $\mathrm{N}$ & $\mathrm{P}$ & $\mathrm{K}$ \\
\hline Soil test value status & Very low & Very low & Low & Very low & Very low & Low \\
\hline STVI (kg/ha) for high yield goal & $91-120$ & $16-20$ & $35-51$ & $61-80$ & $13-16$ & $23-33$ \\
\hline Fertilizer application & $95 \mathrm{~kg} / \mathrm{ha}$ & $18 \mathrm{~kg} / \mathrm{ha}$ & $45 \mathrm{~kg} / \mathrm{ha}$ & $64 \mathrm{~kg} / \mathrm{ha}$ & $14 \mathrm{~kg} / \mathrm{ha}$ & $29 \mathrm{~kg} / \mathrm{ha}$ \\
\hline
\end{tabular}

applied for the three varieties of rice are summarized in the Table 1(c).

The aman rice seedlings were sown in the same potted soils. No As-spiked water was used in this part of the experiment. Only tap water was used. The rice variety BR22 was harvested at 135 days and BR-23 and BR-25 were harvested at 140 days after germination of the seeds. At harvest, the plants and soils from every pot were collected and processed following the same procedures mentioned for the boro season rice plants.

2.3. Laboratory Analyses. Various physical, chemical, and physicochemical properties of the soil samples were analyzed in the laboratory, following the procedures described in [18]. The concentrations of As, N, P, and $\mathrm{K}$ (before and afterexperiment) of the soils and their concentrations in the plants were determined following the procedures described in [18] and in [15]. The quality control/quality assurance (QC/QA) of the analyses was as described in [19]. Statistical analyses for ANOVA were carried out, using the MINITAB 13.0 package.

Total nitrogen of the soil samples was determined by alkali distillation of the Kjeldahl digest. The total phosphorus content of the soil was determined colorimetrically with a spectrophotometer at $490 \mathrm{~nm}$ by developing yellow color with vanadomolybdate after digesting the soil with aquaregia $\left(\mathrm{HCl}: \mathrm{HNO}_{3}=3: 1\right)$.

The total potassium content in soil was determined on the aqua-regia digestion by Flame analyzer.
TABle 2: Physical, chemical, and physicochemical properties of the soil.

\begin{tabular}{lc}
\hline Soil properties & Dhamrai soil \\
\hline $\mathrm{pH}$ & 7.64 \\
$\%$ Sand & 11.6 \\
$\%$ Silt & 41.8 \\
\% Clay & 46.6 \\
Textural class & Silty clay \\
Available P $\left(\mathrm{mg} \mathrm{kg}^{-1}\right)$ & 9.29 \\
Available K $\left(\mathrm{mg} \mathrm{kg}^{-1}\right)$ & 45.55 \\
Total N (\%) & 0.22 \\
Total P $(\%)$ & 0.09 \\
Total K (\%) & 0.69 \\
Total S (\%) & 0.03 \\
OC $(\%)$ & 0.34 \\
OM $(\%)$ & 0.59 \\
Total As $\left(\mathrm{mg} \mathrm{kg}^{-1}\right)$ & 2.32 \\
Water extractable Arsenic $\left(\mathrm{mg} \mathrm{kg}^{-1}\right)$ & Below detection limit \\
\hline
\end{tabular}

The available phosphorus of the soil was extracted by using the Bray \& Kurtz method. P in the extract was estimated calorimetrically following the blue color method using ascorbic acid at $882 \mathrm{~nm}$.

The available potassium in soil was determined by a flame analyzer after extracting the soil with $1 \mathrm{~N}$ ammonium acetate at $\mathrm{pH} 7$. 
TABLE 3: Yield (g) of the boro rice plants.

\begin{tabular}{|c|c|c|c|c|c|}
\hline \multirow{2}{*}{ Variety of rice } & \multirow{2}{*}{ Plant parts } & \multicolumn{4}{|c|}{ Treatments } \\
\hline & & $\mathrm{C}$ & $\mathrm{T}$ & CF & TF \\
\hline \multirow{4}{*}{ BR 29} & Root & 14.5 & 3.7 & 22.6 & 17.6 \\
\hline & Straw & 36.3 & 21.1 & 75.7 & 75.6 \\
\hline & Grain (unhusked) & $9.1^{\mathrm{a}}$ & $4.4^{\mathrm{a}}$ & $24.0^{\mathrm{b}}$ & $20.5^{\mathrm{b}}$ \\
\hline & Total & $59.9^{a}$ & $29.12^{\mathrm{a}}$ & $122.6^{\mathrm{b}}$ & $113.7^{\mathrm{b}}$ \\
\hline \multirow{4}{*}{ BR 35} & Root & 24.5 & 6.8 & 17.3 & 15.7 \\
\hline & Straw & 58.8 & 37.7 & 86.8 & 55.9 \\
\hline & Grain (unhusked) & $11.2^{\mathrm{a}}$ & $13.7^{\mathrm{a}}$ & $32.9^{\mathrm{b}}$ & $34.1^{\mathrm{b}}$ \\
\hline & Total & $94.5^{\mathrm{a}}$ & $58.2^{\mathrm{b}}$ & $137.0^{\mathrm{b}}$ & $105.7^{\mathrm{ab}}$ \\
\hline \multirow{4}{*}{ BR 36} & Root & 8.9 & 7.6 & 28.2 & 17.7 \\
\hline & Straw & 26.4 & 20.4 & 74.9 & 83.1 \\
\hline & Grain (unhusked) & $14.5^{\mathrm{a}}$ & $15.7^{\mathrm{a}}$ & $52.3^{\mathrm{b}}$ & $42.9^{\mathrm{b}}$ \\
\hline & Total & $49.8^{\mathrm{a}}$ & $43.7^{\mathrm{a}}$ & $155.4^{\mathrm{b}}$ & $143.7^{\mathrm{b}}$ \\
\hline
\end{tabular}

C: absolute control, T: As-treatment, CF: As-control, TF: Fertilizer treatment.

TABLE 4: Yield (g) of the aman rice plants.

\begin{tabular}{|c|c|c|c|c|c|}
\hline \multirow{2}{*}{ Variety of rice } & \multirow{2}{*}{ Plant parts } & \multicolumn{4}{|c|}{ Treatments } \\
\hline & & $\mathrm{C}$ & $\mathrm{T}$ & $\mathrm{CF}$ & $\mathrm{TF}$ \\
\hline \multirow{4}{*}{ BR 22} & Root & 4.9 & 4.7 & 7.5 & 5.5 \\
\hline & Straw & 11.6 & 9.0 & 14.4 & 12.3 \\
\hline & Grain (unhusked) & $5.7^{\mathrm{a}}$ & $5.4^{\mathrm{a}}$ & $8.0^{\mathrm{a}}$ & $6.2^{\mathrm{a}}$ \\
\hline & Total & $22.2^{\mathrm{a}}$ & $19.1^{\mathrm{a}}$ & $29.9^{a}$ & $24.0^{\mathrm{a}}$ \\
\hline \multirow{4}{*}{ BR 23} & Root & 5.8 & 5.8 & 6.0 & 5.9 \\
\hline & Straw & 10.9 & 10.2 & 12.0 & 11.1 \\
\hline & Grain (unhusked) & $5.6^{\mathrm{a}}$ & $5.1^{\mathrm{a}}$ & $6.7^{\mathrm{a}}$ & $5.8^{\mathrm{a}}$ \\
\hline & Total & $22.3^{\mathrm{a}}$ & $21.1^{\mathrm{a}}$ & $24.7^{\mathrm{a}}$ & $22.8^{\mathrm{a}}$ \\
\hline \multirow{4}{*}{ BR 25} & Root & 5.2 & 5.1 & 6.1 & 5.9 \\
\hline & Straw & 10.9 & 10.9 & 13.3 & 13.1 \\
\hline & Grain (unhusked) & $5.4^{\mathrm{a}}$ & $5.4^{\mathrm{a}}$ & $6.2^{\mathrm{a}}$ & $6.0^{\mathrm{a}}$ \\
\hline & Total & $21.5^{\mathrm{a}}$ & $21.4^{\mathrm{a}}$ & $25.6^{\mathrm{a}}$ & $25.0^{\mathrm{a}}$ \\
\hline
\end{tabular}

C: absolute control, T: As-treatment, CF: As-control, TF: Fertilizer treatment.

TABle 5: Concentration of As $\left(\mathrm{mg} \mathrm{kg}^{-1}\right)$ in boro rice plants.

\begin{tabular}{|c|c|c|c|c|c|}
\hline \multirow{2}{*}{ Variety of rice } & \multirow{2}{*}{ Plant parts } & \multicolumn{4}{|c|}{ Treatments } \\
\hline & & $\mathrm{C}$ & $\mathrm{T}$ & $\mathrm{CF}$ & $\mathrm{TF}$ \\
\hline \multirow{3}{*}{ BR 29} & Root & 10.04 & 51.95 & 27.45 & 32.36 \\
\hline & Straw & 2.48 & 11.90 & $\mathrm{BDL}$ & 2.78 \\
\hline & Grain (unhusked) & 0.32 & 0.97 & 0.20 & 0.55 \\
\hline \multirow{3}{*}{ BR 35} & Root & 12.90 & 69.04 & 23.84 & 35.70 \\
\hline & Straw & 1.55 & 3.10 & 1.88 & 2.33 \\
\hline & Grain (unhusked) & $\mathrm{BDL}$ & 1.19 & $\mathrm{BDL}$ & 0.12 \\
\hline \multirow{3}{*}{ BR 36} & Root & 11.34 & 78.64 & 22.02 & 30.16 \\
\hline & Straw & 0.91 & 4.15 & 0.84 & 4.15 \\
\hline & Grain (unhusked) & 0.03 & 0.39 & $\mathrm{BDL}$ & 0.12 \\
\hline
\end{tabular}

C: absolute control, T: As-treatment, CF: As-control, TF: Fertilizer treatment, BDL: Below detection limit. 
TABLE 6: Total As content ( $\mathrm{mg} \mathrm{kg}^{-1}$ ) in the soils after harvest of the boro rice.

\begin{tabular}{lcccc}
\hline \multirow{2}{*}{ Soil under } & \multicolumn{4}{c}{ Treatments } \\
& $\mathrm{C}$ & $\mathrm{T}$ & $\mathrm{CF}$ & $\mathrm{TF}$ \\
\hline BR-29 & 2.24 & 5.93 & 3.63 & 7.48 \\
BR-35 & 2.06 & 4.80 & 3.19 & 6.98 \\
BR-36 & 2.02 & 7.68 & 3.02 & 9.46 \\
\hline
\end{tabular}

C: absolute control, T: As-treatment, CF: As-control, TF: Fertilizer treatment.

TABLE 7: Water extractable As $\left(\mathrm{mg} \mathrm{kg}^{-1}\right)$ in the soils after harvest of boro rice.

\begin{tabular}{lcccc}
\hline \multirow{2}{*}{ Soil under } & \multicolumn{4}{c}{ Treatments } \\
& $\mathrm{C}$ & $\mathrm{T}$ & $\mathrm{CF}$ & $\mathrm{TF}$ \\
\hline BR-29 & 0.052 & 0.074 & 0.06 & 0.081 \\
BR-35 & BDL & BDL & 0.02 & 0.067 \\
BR-36 & 0.001 & 0.002 & 0.01 & 0.024 \\
\hline
\end{tabular}

C: absolute control, T: As-treatment, CF: As-control, TF: Fertilizer treatment, BDL: Below detection limit.

Total arsenic content of the soils was extracted by aqua-regia (concentrated $\mathrm{HCl}$ : concentrated $\mathrm{HNO}_{3}=3: 1$ ) digestion and that of plant samples by boiling $\mathrm{HNO}_{3}$. The determination of As was done by hydride generation atomic absorption spectrophotometer (AAS). It needs to be mentioned here that due to smaller number of grains, the analyses were made on the unhusked grains.

\section{Results and Discussion}

3.1. Soil Properties. The collected soil sample was analyzed to ascertain the levels of nutrients as well as other elements present and the values are shown in Table 2.

3.2. Yield of Rice Plants. Marked differences were observed in the mean yield of the rice plants between the boro and aman seasons. The yield of the boro season rice varieties was much higher compared to the yield of the aman season rice varieties (Tables 3 and 4). The use of balanced fertilizers increased the yield of the crops, while the use of As-laden irrigation water reduced the crop yield indicating the fact that As played a negative role on the growth of the rice varieties. The effect of treatments on the dry matter production of the varieties in both the seasons followed the order: $\mathrm{CF}>\mathrm{TF}>\mathrm{C}>\mathrm{T}$.

The effect of the treatments on the total and grain yield of the boro rice was found to be highly significant $(P<$ $.01)$. The LSDs(0.05) are 32.09 for total and 11.32 for grain yield, respectively. The varieties showed insignificant yield difference when total yield was considered; however, the response was found to be significant when the grain yield was considered $(P=.01)$, with the LSD $(0.05)$ value being 9.8 . For the aman rice, there was no significant difference in yields (total and grain) among the varieties although treatment had significant $(P<.05)$ effects, with the LSD $(0.05)$ value being 3.1. Irrespective of the season, the treatments as well as the varieties showed highly significant $(P \leq .01)$ effects on the dry matter production of the plants.
3.3. Accumulation of As in the Boro Rice. Elevated levels of As was found to be accumulated in the boro varieties under all the treatment conditions (Table 5). The roots of the rice plants accumulated the highest amount of As (78.2 to 99.3\% of the total content) followed by straw (3.7 to $19.3 \%$ of the total content) and unhusked rice grains (up to $1.2 \%$ of the total content). It needs to be mentioned here that though husked rice grain is consumed, we have analyzed the grain unhusked as the number of grains obtained was not big enough. Moreover, a proportion of arsenic in the husk and in the grain is maintained that allows assessing the extent of As contamination in the husked rice (brown rice) grain [20]. Husks contain relatively smaller amount of As compared to the brown rice. So, the present observation obviously indicates an accumulation of As in the rice grain that will enter into the food chain. Similar observations have also been made by others [21-23]. The study also corroborated to our [13] earlier observation that the As that accumulates in the plants follows the order: root $>$ straw $>$ husk > grain. This accumulation pattern, as it appears, is irrespective of the source of arsenic in the growth medium or of the varieties of rice plants. Treatments were found to have highly significant $(P<.01)$ effects on the accumulation of As, whereas the varieties did not show any significant difference. The effects of the treatments and of the rice varieties on the grain As contents were found to be insignificant. The level of As content in all the rice varieties was in the order of the treatments: $\mathrm{T}>\mathrm{TF}>\mathrm{CF}>\mathrm{C}$ (Table 5).

In the absolute control $(\mathrm{C})$ condition, some As accumulation were found for all the plants and that could perhaps be due to the background As in the soil $\left(2.32 \mathrm{mg} \mathrm{kg}^{-1}\right)$ (Table 5). The total accumulation of As in BR 29, BR 35, and BR 36 plants was found to have increased by around 405,400 , and $577 \%$, respectively, for the combination of As treatment and no added fertilizers ( $\mathrm{T}$ ) compared to absolute control. This accumulation, however, was reduced by 227,229 , and $397 \%$, respectively, for the varieties when balanced fertilizers were added to the medium (TF). This indicates that the use of balanced fertilizers plays a positive role to reduce arsenic accumulation in rice. Under fertilized condition with no As treatment (CF), accumulation of As in BR 29, BR 35 and BR 36 was also found, respectively, to be 115,78 , and $86 \%$, higher than the accumulation under the absolute control (C) condition. This higher accumulation could possibly be due to the presence of arsenic as impurity in the fertilizers used.

After the harvest of the boro crop, analysis of the potted soils showed the loading effect of arsenic through irrigation water used during the boro season (Tables 6 and 7). Higher amounts of As were found to remain in the soils treated with fertilizers compared to the nonfertilized soils. It is also noted that water extractable As was also detected in the pot soil after boro season. The soil originally did not yield any water extractable As.

3.4. Accumulation of As in the Aman Rice. All the varieties of aman rice grown in the same pot soils used for the previous boro rice cultivation were observed to accumulate some As, although no further As was added to the soils during the aman season. The roots of the rice plants accumulated the 
TABLE 8: Concentration of As $\left(\mathrm{mg} \mathrm{kg}^{-1}\right)$ in the aman rice plants.

\begin{tabular}{|c|c|c|c|c|c|}
\hline \multirow{2}{*}{ Variety of rice } & \multirow{2}{*}{ Plant parts } & \multicolumn{4}{|c|}{ Treatments } \\
\hline & & $\mathrm{C}$ & $\mathrm{T}$ & $\mathrm{CF}$ & $\mathrm{TF}$ \\
\hline \multirow{3}{*}{ BR 22} & Root & 2.63 & 20.18 & 4.75 & 7.95 \\
\hline & Straw & 0.50 & 0.79 & 0.51 & 0.53 \\
\hline & Grain (unhusked) & 0.04 & 2.02 & 0.14 & 0.24 \\
\hline \multirow{3}{*}{ BR 23} & Root & 5.05 & 14.63 & 6.50 & 8.60 \\
\hline & Straw & 1.71 & 2.56 & 2.20 & 2.23 \\
\hline & Grain (unhusked) & 0.07 & 0.48 & 0.12 & 0.24 \\
\hline \multirow{3}{*}{ BR 25} & Root & 4.15 & 41.28 & 8.20 & 30.90 \\
\hline & Straw & 0.40 & 1.10 & 0.60 & 0.61 \\
\hline & Grain (unhusked) & 0.01 & 0.19 & 0.15 & 0.17 \\
\hline
\end{tabular}

C: absolute control, T: As-treatment; CF: As-control; TF: Fertilizer treatment.

TABLE 9: As $\left(\mathrm{mg} \mathrm{kg}^{-1}\right)$ in the soils after harvest of the aman rice.

\begin{tabular}{lcccc}
\hline \multirow{2}{*}{ Variety of rice } & \multicolumn{4}{c}{ Treatments } \\
& $\mathrm{C}$ & $\mathrm{T}$ & $\mathrm{CF}$ & $\mathrm{TF}$ \\
\hline BR-22 & 0.04 & 3.82 & 0.87 & 3.17 \\
BR-23 & 0.15 & 4.23 & 0.27 & 3.96 \\
BR-25 & 0.01 & 4.64 & 0.18 & 4.13 \\
\hline
\end{tabular}

C: absolute control, T: As-treatment, CF: As-control, TF: Fertilizer treatment.

highest amount of As (73.70 to $97.54 \%$ of the total content) followed by straw ( 1.93 to $25.04 \%$ of the total content) and unhusked rice grains ( 0.22 to $8.79 \%$ of the total content) (Table 8). The accumulation pattern is similar to that of the boro season rice and is also irrespective of the source of arsenic in the growth medium or of the varieties of rice.

The rice plants in the aman season accumulated lower amounts of As compared to the rice plants in the boro season. This is obvious as no As-treated irrigation water was used in the aman season. This indicates that the As added through irrigation water during the boro season and accumulated in the soil is carried over to the next crop. Imamul Huq et al. [12] and Williams et al. [9] also found that As levels in boro season rice were more elevated than aman season rice. This is perhaps due to higher bioaccessibility of As in irrigated water during boro season. That water-borne As is more bioaccessible than soil- As has been shown by Imamul Huq and Naidu [24]. However, like the boro season rice, the levels of As content in all the aman season rice were in the order of the treatments: $\mathrm{T}>\mathrm{TF}>\mathrm{CF}>\mathrm{C}$ (Table 8).

The treatments were found to have significant $(P<.05)$ effects on the accumulation of As in the plants, whereas the varieties did not show any significant effect. The effects of the treatments and of the rice varieties on the grain As contents were found to be insignificant.

The aman varieties, like the boro ones, also accumulated the lowest amounts of As for the absolute control condition (C) than for the other treatments (Table 8). Arsenic accumulation increased by around 625,159 , and $834 \%$, respectively, for BR 22, BR 23, and BR 25 varieties for As treatment, while the accumulation was reduced by 450,97 , and $239 \%$, respectively, for the varieties where balanced fertilizer was used (TF). Balanced fertilization was able to reduce the grain As content by around 88,50 , and $11 \%$, respectively, in the BR 22, BR 23, and BR 25 aman rice.

After harvest of the aman plants, residual As was noted in the soils, being the maximum under the As-treated $(\mathrm{T})$ soils followed by TF, CF, and C soils (Table 9).

3.5. Accumulation of As by Boro Rice. The accumulation was calculated by multiplying the concentrations of As in dry matter with the total dry weight of the plants and the results are expressed as mg per pot. The minimum accumulation of As by the boro season rice was found for the absolute control soils (Table 10). In the soils where only fertilizers were added, higher amounts of As were taken up by the boro plants, the reason perhaps could be related to the higher yield effected due to the balanced fertilizers. In the As-treated soils, total accumulation of As into plants was found to have increased by around 145,207 , and $495 \%$, respectively, for the varieties of BR 29, BR 35, and BR 36, while grain As accumulation in BR 29 was increased by $33 \%$. In the presence of balanced fertilization where the pots were watered with As contaminated irrigation water (TF), the data showed aberrant results. An increase in the As uptake in this case, though balanced fertilization was followed, could possibly be related to the elevated yields of the boro rice plants.

3.6. Accumulation of As by Aman Season Rice. In the aman rice, the As transfer from the soil to the roots, straw, and grains was lower than that observed in the preceding boro season. For the aman rice varieties, grain-As accumulation per pot ranged from 0.0001 to $0.0108 \mathrm{mg}$ As (Table 11). The lowest As uptake was noticed for the plants with no imposed treatment $(\mathrm{C})$, while the highest amount of As was taken up by the plants grown with As-treated irrigation water. Addition of fertilizers in the control soil also showed an increased uptake of As by the plants. On the other hand, balanced fertilization in the As-treated soil reduced total As uptake into the BR 22, BR 23, and BR 25 varieties by around 56,87 , and $6 \%$, respectively, and grain As uptake by around 9 to $87 \%$. This again indicates that the presence of balanced 
TABle 10: Accumulation of As (mg/pot) in boro rice plants.

\begin{tabular}{lccccr}
\hline Variety of rice & Plant parts & C & T & CF & TF \\
\hline BR 29 & Grain (unhusked) & 0.0029 & 0.0043 & 0.0048 & 0.0113 \\
BR 35 & Grain (unhusked) & - & 0.0016 & - & 0.0406 \\
BR 36 & Grain (unhusked) & 0.0004 & 0.0061 & - & 0.0051 \\
\hline
\end{tabular}

C: absolute control, T: As-treatment, CF: As-control, TF: Fertilizer treatment.

TABLe 11: Accumulation of As (mg/pot) by the aman rice plants.

\begin{tabular}{llcccr}
\hline Variety of rice & Plant parts & \multicolumn{3}{c}{ Treatments } & C \\
& Grain (unhusked) & 0.0002 & 0.0108 & 0.0009 & 0.0014 \\
\hline BR 22 & Grain (unhusked) & 0.0004 & 0.0025 & 0.0008 & 0.0014 \\
BR 23 & Grain (unhusked) & 0.0001 & 0.0011 & 0.0012 & 0.0010 \\
BR 25 &
\end{tabular}

C: absolute control, T: As-treatment, CF: As-control, TF: Fertilizer treatment.

fertilizers in the growth medium can substantially reduce the uptake of As into rice when As is present in the growth medium.

3.7. Comparison of As Accumulation into the Two Season Rice Varieties. Remarkable variation in the concentration of arsenic was observed between the boro and the aman season rice varieties. Among the three boro varieties, BR-36 was found to be the most sensitive to arsenic treatment. The response to balanced fertilization in reducing As accumulation into rice was also found to be the most marked for BR-36. On the other hand, among the three aman varieties, BR-25 appeared to be the most sensitive to the presence of arsenic in the growth medium and BR-22 was found to be the most efficient variety to respond to the effect of balanced fertilization to minimize As accumulation. However, the other varieties of boro and aman rice also showed good response to the use of balanced fertilizers and accumulated less As compared to the As-treated (T) plants.

In the boro season, the application of As contaminated irrigation water provided water soluble As which may have supplemented the inherent bioavailability of As in the soil to rice, allowing more As to be transferred from soil to rice plants in this case. In the rice grown in the aman season, the As transfer from the soil to roots and straw were lower, in most cases, than that which occurred in the preceding boro season. This could be related to the use of As free water. It appears that such water does not provide water soluble As to supplement the bioavailable fraction of soil As.

\section{Conclusion}

The study substantiates that balanced fertilization can improve crop yield through reduced arsenic accumulation in rice. From the study it is also apparent that boro season rice accumulates high amount of arsenic if irrigated with arsenic contaminated water and it promotes a buildup of arsenic in soil which can cause the following aman season rice to accumulate a considerable amount of the element although
As-free or low-As-laden irrigation water is used. However, in both situations, As accumulation in rice grain could be alleviated through balanced fertilization. Thus, balanced fertilization practice in the rice fields could be a good strategy to mitigate arsenic accumulation in the food chain. Improving fertilizer use efficiency is essential and should be a common practice in farming. Further field studies with balanced fertilization practices need to be carried out with more of the boro and aman rice varieties currently cultivated in Bangladesh to properly address the carryover effects of arsenic in irrigation water on the subsequent accumulation of arsenic in the affected regions.

\section{References}

[1] S. M. Imamul Huq, M. B. Abdullah, and J. C. Joardar, "Bioremediation of arsenic toxicity by algae in rice culture," Land Contamination and Reclamation, vol. 15, no. 3, pp. 327333, 2007.

[2] BADC (Bangladesh Agricultural Development Corporation), Survey Report on Irrigation Equipment and Irrigated area in Boro/2001 Season, Bangladesh Agricultural Development Corporation, 2002.

[3] S. M. Imamul Huq, A. Bulbul, M. S. Choudhury, S. Alam, and S. Kawai, "Arsenic bioaccumulation in a green algae and its subsequent recycling in soil of Bangladesh," in Natural Arsenic in Groundwater: Occurrence, Remediation and Management, J. Bundschuh and P. Bhattacharya, Eds., pp. 119-124, A. A. Balkema, New York, NY, USA, 2005.

[4] M. B. Alam and M. A. Sattar, "Assessment of arsenic contamination in soils and waters in some areas of Bangladesh," Water Science and Technology, vol. 42, no. 7-8, pp. 185-192, 2000.

[5] J. M. Duxbury, A. B. Mayer, J. G. Lauren, and N. Hassan, "Food chain aspects of arsenic contamination in Bangladesh: effects on quality and productivity of rice," Journal of Environmental Science and Health A, vol. 38, no. 1, pp. 61-69, 2003.

[6] A. A. Meharg and M. Rahman, "Arsenic contamination of Bangladesh paddy field soils: implications for rice contribution to arsenic consumption," Environmental Science and Technology, vol. 37, no. 2, pp. 229-234, 2003. 
[7] S. M. Imamul Huq and R. Naidu, "Arsenic in ground water and contamination of the food chain: Bangladesh scenario," in Natural Arsenic in Ground Water: Occurrence, Remediation and Management, J. Bundschuh, P. Bhattacharya, and D. Chandrasekharam, Eds., pp. 95-101, Balkema, Leiden, The Netherlands, 2005.

[8] S. M. I. Huq, J. C. Joardar, S. Parvin, R. Correll, and R. Naidu, "Arsenic contamination in food-chain: transfer of arsenic into food materials through groundwater irrigation," Journal of Health, Population and Nutrition, vol. 24, no. 3, pp. 305-316, 2006.

[9] P. N. Williams, M. R. Islam, E. E. Adomako et al., "Increase in rice grain arsenic for regions of Bangladesh irrigating paddies with elevated arsenic in groundwaters," Environmental Science and Technology, vol. 40, no. 16, pp. 4903-4908, 2006.

[10] S. M. Imamul Huq, J. C. Joardar, and A. F. M. Manzurul Hoque, "Seasonal effect on the load in soil and subsequent transfer of arsenic to rice," Land Contamination and Reclamation, vol. 16, no. 4, pp. 357-363, 2008.

[11] M. J. Abedin, J. Feldmenn, and A. Meharg, "Uptake kinetics of arsenic species in rice (Oryza sativa L.) plants," Plant Physiology, vol. 128, pp. 1120-1287, 2002.

[12] S. M. Imamul Huq, H. A. Haque, J. C. Joardar, and M. S. A. Hossain, "Arsenic accumulation in rice grown in aman and boro seasons," Dhaka University Journal of Biological Sciences, vol. 16, no. 2, pp. 91-97, 2007.

[13] S. M. Imamul Huq, U. K. Shila, and J. C. Joardar, "Arsenic mitigation strategy for ice, using water regime management," Land Contamination and Reclamation, vol. 14, no. 4, pp. 805813, 2006.

[14] S. M. Imamul Huq and J. C. Joardar, "Effect of balanced fertilization on arsenic and other heavy metals uptake in rice and other crops," Bangladesh Journal of Agriculture and Environment, vol. 4, pp. 177-191, 2008.

[15] S. M. Imamul Huq, S. Al-Mamun, J. C. Joardar, and S. A. Hossain, "Remediation of soil arsenic toxicity in Ipomoea aquatica, using various sources of organic matter," Land Contamination and Reclamation, vol. 16, no. 4, pp. 333-341, 2008.

[16] M. R. Rahman, Soils of Bangladesh, Darpon, Dhaka, Bangladesh, 2005.

[17] BARC (Bangladesh Agricultural Research Council), "Fertilizer recommendation guide-2005," Publication no. 45. Farmgate, New Airport Road, Dhaka-1215. pp. 1-42, 2005.

[18] S. M. Imamul Huq and M. D. Alam, A Handbook on Analyses of Soil, Plant, and Water. BACER-DU, University of Dhaka, Dhaka, Bangladesh, 2005.

[19] M. T. A. Chowdhury, L. Nesa, M. A. Kashem, and S. M. Imamul Huq, "Assessment of the phytoavailability of $\mathrm{Cd}, \mathrm{Pb}$ and $\mathrm{Zn}$ using various extraction procedures," Pedologist, vol. 53, no. 3, pp. 80-95, 2010.

[20] S. M. Imamul Huq, "Fate of arsenic in irrigation water and its potential impact on the food chain," in Arsenic Contamination of Ground Water: Mechanism, Analysis and Remediation, S. Ahuj, Ed., pp. 23-49, John Wiley \& Sons, Hoboken, NJ, USA, 2008.

[21] S. M. Imamul Huq, K. M. Ahmed, N. Sultana, and R. Naidu, "Extensive arsenic contamination in ground water and soils of Bangladesh," in Proceedings of the Arsenic in the Asia-Pacific Region Workshop, pp. 94-96, Adelaide, Australia, November 2001.
[22] A. R. Marin, P. H. Masscheleyn, and W. H. Patrick Jr., "The influence of chemical form and concentration of arsenic on rice growth and tissue arsenic concentration," Plant and Soil, vol. 139, no. 2, pp. 175-183, 1992.

[23] Z. M. Xie and C. Y. Huang, "Control of arsenic toxicity in rice plants grown on an arsenic-polluted paddy soil," Communications in Soil Science and Plant Analysis, vol. 29, no. 15-16, pp. 2471-2477, 1998.

[24] S. M. Imamul Huq and R. Naidu, "Arsenic in ground water of Bangladesh: contamination in the food chain," in Arsenic Contamination: Bangladesh Perspective, M. Feroze Ahmed, Ed., pp. 203-226, ITN-Bangladesh, Centre for Water Supply and Waste Management, BUET, Dhaka, Bangladesh, 2003. 

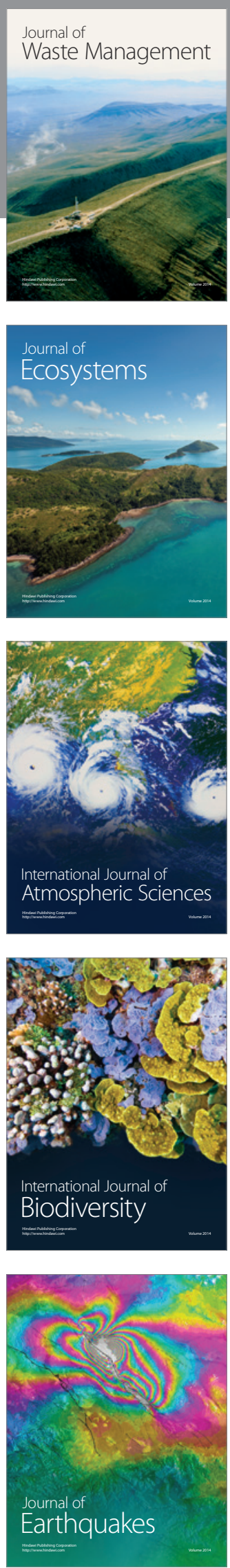
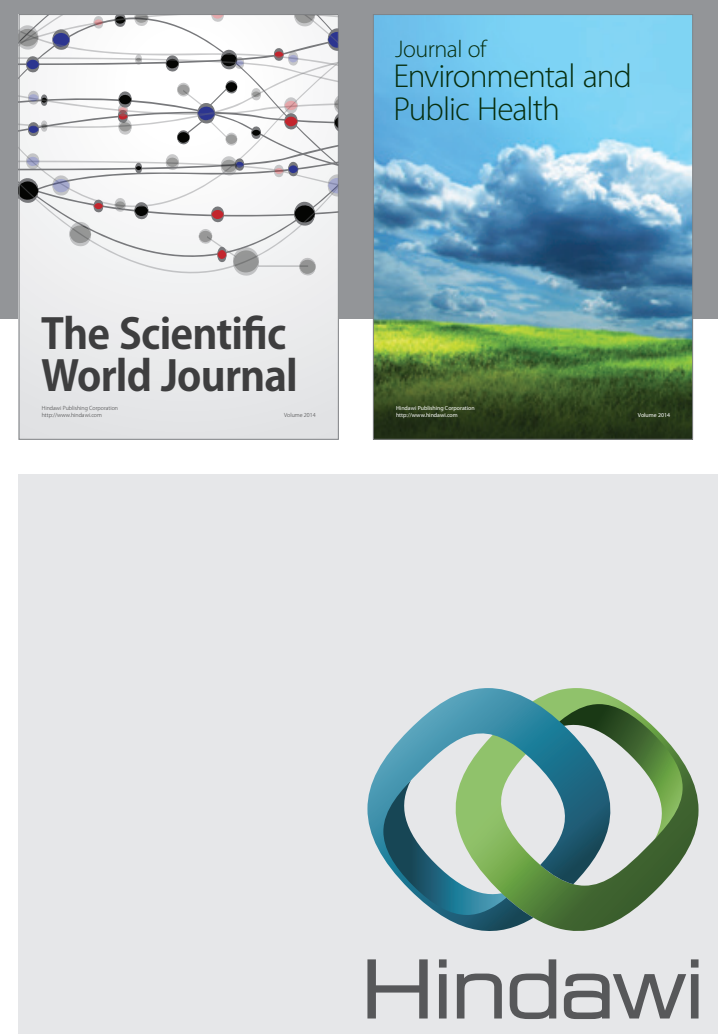

Submit your manuscripts at

http://www.hindawi.com
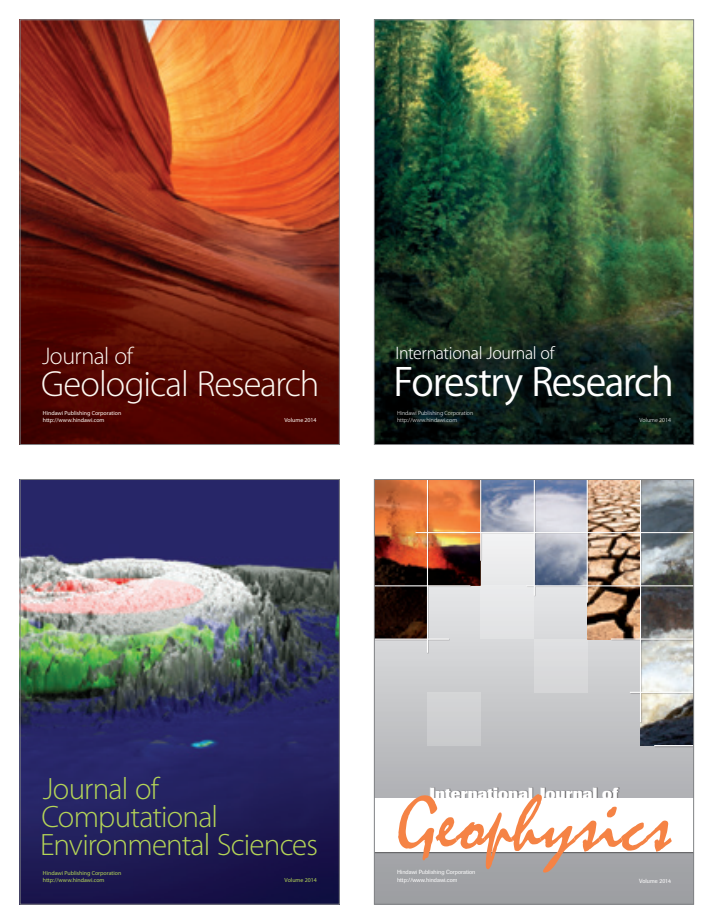
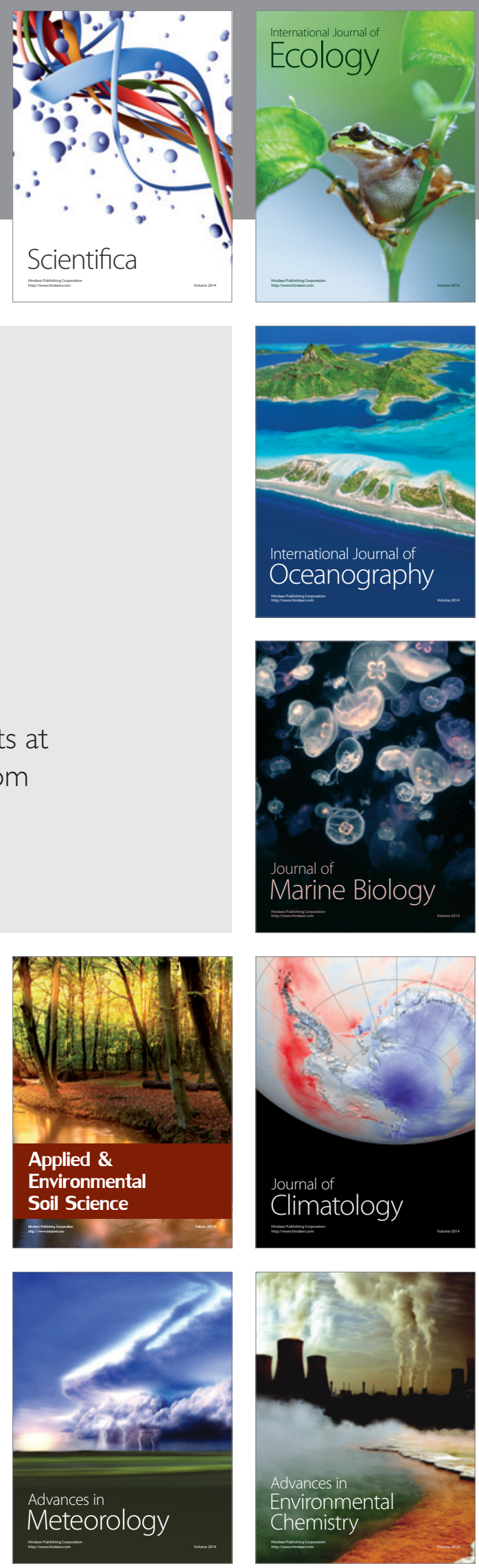